\title{
25 Research Square \\ Developmental Trends in Early Childhood and Their Predictors from an Indian Birth Cohort
}

Beena Koshy ( $\square$ beenakurien@cmcvellore.ac.in )

Christian Medical College and Hospital Vellore https://orcid.org/0000-0002-9058-1392

\section{Manikandan Srinivasan}

Christian Medical College and Hospital Vellore

\section{Anuradha Bose}

Christian Medical College and Hospital Vellore

\section{Sushil Mathew John}

Christian Medical College and Hospital Vellore

\section{Venkata Raghava Mohan}

Christian Medical College

\section{Reeba Roshan}

Christian Medical College and Hospital Vellore

\section{Karthikeyen Ramanujam}

Christian Medical College and Hospital Vellore

\section{Gagandeep Kang}

Christian Medical College and Hospital Vellore

\section{Research article}

Keywords: early childhood, developmental trends, socio-economic status, home environment, maternal factors

Posted Date: July 24th, 2020

DOI: https://doi.org/10.21203/rs.3.rs-46054/v1

License: (9) This work is licensed under a Creative Commons Attribution 4.0 International License.

Read Full License

Version of Record: A version of this preprint was published at BMC Public Health on June 6th, 2021. See the published version at https://doi.org/10.1186/s12889-021-11147-3. 


\section{Abstract}

Background: Early childhood developmental pattern analyses not only project future cognition potential, but also identify potential risks for possible intervention. There is a paucity of literature evaluating developmental trends in the low and middle income country settings.

Methods: Trends of early childhood development at 6, 15, 24 and 36 months of age and their predictors were explored in a longitudinal community-based birth cohort study in an urban slum in Vellore, South India. Development was assessed using the Bayley Scales of Infant and Toddler Development-III (BSIDIII).

Results: The birth cohort enrolled 251 children with a 94\%, 91\% and 87\% follow-up at 6, 24 and 36 months respectively. Child development domains of cognition, language, motor and social skills showed a significant decline in scores between 6 and 36 months of age. Cognition change was maximum augmented by higher socio-economic status (SES) and nurturing home environment while stunting had the maximum negative impact. Higher maternal cognition, higher SES, and caregiver responsivity positively contributed to language change over time, while higher maternal depression contributed negatively. An enriching home environment, growth parameters and blood iron status had high association with change in motor skills.

Conclusions. A triple intervention plan to enhance home environment and nurturance, maternal education and well-being, and early childhood nutrition supplementation might prevent child developmental decline in high risk settings.

\section{Introduction}

It is estimated that around 250 million young children living in the low and middle income countries (LMIC) risk poor development and sub-optimal livelihood potential [1, 2] because of exposure to twin risks of extreme poverty and stunting [3]. Describing developmental trajectory patterns in the LMIC not only helps in understanding developmental variations different from conventional standards, but also aids in identifying sensitive periods and specific risk factors including adverse childhood experiences. Regionspecific analysis of developmental trajectory patterns can in addition help to custom-make specific developmental intervention, which can be later incorporated into public health policy.

Sensitive periods for optimal childhood development include the time period from conception to two years of age considered the first- 1000 days of life [4] and from two to five years of age, the second1000 days of life $[5,6]$. Large multi-national birth cohort studies have shown complex interactions among early childhood infections, nutritional intake, family socio-economic status and home environment affecting cognition at two years [7] as well as five years of age [8]. Risk factors including foetal growth restriction manifesting as low birth weight [9], absolute poverty [2], early childhood stunting [2, 5], micronutrient deficiency [10], poor sanitation [11], diarrhoea [12,13], maternal depression [14] and sub- 
optimal home environment $[15,16]$ can adversely impact early child development with persisting effects on later school cognition, learning and behaviour $[1,2,5]$.

Early childhood developmental trajectory analyses have been predominantly restricted to cognition $[9,17$, 18], with a few evaluating other developmental domains such as social skills [19]. Group based trajectory modelling of a large Chinese birth cohort showed four different patterns of cognition paths in the first 24 months of life [9], while longitudinal social profiles of Japanese children between two and five years of age showed three different trajectories [19]. Development of neuropsychological functions in Indian children was described as "non-linear, heterogeneous and protracted" in a cross-sectional study [20]. There have been few studies exploring evolution of all domains of development over time in the early years, especially in a LMIC setting. The current study was planned to evaluate the trends of child developmental domains of cognition, language, social and motor skills in the first three years of life and analyse their predictors. It is hypothesized that socio-economic status, home environment, maternal cognition and micronutrient status will influence developmental domains.

\section{Methods}

\section{Settings and subjects}

The present study was done as an independent sub-analysis of a large prospective, multinational longitudinal birth cohort study conducted across eight different nations across the world -'The Etiology, Risk Factors and Interactions of Enteric Infections and Malnutrition and the Consequences for Child Health and Development (MAL-ED) Network'[21]. The Indian study site was a densely populated urban slum in Vellore, South India [22]. For birth enrolment, the population of 12,000 was covered and pregnant women identified by a door-to-door survey. Consenting mothers were invited to participate in the study after an informed consent immediately after birth, by consecutive sampling. The exclusion criteria included multiple pregnancies, family's existing plans to migrate out during study period, medical comorbidities in the index child, another child already registered in the study, and mothers not available to provide necessary informed consent. Trained field workers visited recruited children twice a week till their second birthday for active disease monitoring and surveillance as per the MAL-ED protocol, with subsequent follow-ups. The initial birth cohort recruitment was conducted in Vellore between March 2010 and February 2012 and enrolled 251 newborns. The original birth cohort enrollment and consequent follow-ups were approved by the Institutional Review Board of Christian Medical College, Vellore and children were recruited at each stage after informed parental consent.

\section{Measures}

\section{Bayley Scales of Infant and Toddler Development-III (BSID- III)}


The Bayley Scales of Infant and Toddler Development-III (BSID-III) assesses development in the domains of motor, language, cognition and social skills between 1 and 42 months of age [23]. Prior to administration, the BSID-III was culturally adapted, translated, back-translated and piloted. The testing was conducted by a single trained clinical psychologist for each time point in a child-friendly site in the community clinic. Quality control was assured by reviews of video-recorded tests having $10 \%$ being reviewed locally and 5-6\% centrally [24]. BSID-III was administered at 6, 15, 24 and 36 months of age. For each time point, psychologist administered items pertaining to cognition, motor (gross motor and fine motor) and language (receptive and expressive) components. Socio-emotional scale was parent reported and correspondingly scored.

Cognition component measures exploration and manipulation of toys, concept formation, object relatedness and memory. Motor domain measures gross motor functions of sitting, walking, running, etc and fine motor functions of sensorimotor development and hand skills. Receptive language constitutes receptive abilities and comprehension of the child, while expressive language includes expressive abilities in spoken language and other communication modes. Socio-emotional domain analyses social and interactive skills of the child [23]. Individual domain quotient was calculated from the raw score using child's chronological age.

\section{The WAMI measure for socio-economic status}

The WAMI is a simplified measure of socio-economic status (SES) developed during the MAL-ED study, with components of access to improved Water and sanitation, Assets, Maternal education and total household Income [25]. The WAMI questionnaire was translated and piloted prior to the administration. A trained field worker visited the home and administered the measure at 6, 12, 18, 24 and 36 months of child's age. The questionnaire for WAMI was translated to Tamil and back-translated before administration by a trained field worker. The final score was calculated from these variables, which was then converted to a standardized score ranging from 0 to 1 .

\section{The HOME Scale}

The Home Observation for the Measurement of the Environment (HOME) scale (Infant/Toddler version) analyses the home environment of the child including stimulation and support and is considered the gold standard with good psychometrics $[26,27]$. This observed measure analyses specifically mother-child interactions including responsiveness.

The modified version has six subscales consisting of total 48 items with subscales of appropriate play materials, avoidance of restriction and punishment, organization of the environment, parental involvement, responsiveness to parent, and variety in daily stimulation [28]. The measure was translated and piloted in the community prior to its administration. A trained social worker observed the home environment for 45-60 minutes in the morning and completed the HOME scale with supplementary 
information using a mother/caregiver interview as per the MAL-ED study protocol $[29,30]$. HOME scale was administered at 6,24 and 36 months of child's age.

\section{Raven's progressive matrices}

The Raven's progressive matrices, a scale of non-verbal reasoning ability was used to assess maternal cognition at 6-8 months of child's age [31]. This culture-fair test was administered by a trained psychologist to mothers in a centrally located distraction-free room in the community clinic as per the MAL-ED study protocol [29]. Raw scores were used for analyses.

\section{The Self Reporting Questionnaire-20}

The Self Reporting Questionnaire-20 (SRQ-20), developed by the World Health Organisation (WHO) to assess depressive symptoms in low-resource settings, was used to assess maternal psychological disturbances at 1,6, 15, 24 and 36 months of child age [32]. A trained social worker administered the measure at home.

\section{Blood collection and analysis}

Blood samples were collected at 7, 15, 24, 36 and 60 months. Samples were tested for hemoglobin (7, 15, 24, and 36 months); ferritin assays (at 7, 15 and 24 months) and blood lead levels (at 15, 24 and 36 months). Hemocue ${ }^{\circledR} \mathrm{Hb} 301$ kit (azidemethemoglobin method) was used to estimate hemoglobin using a drop of blood immediately after collection of blood in the community study clinic. The blood samples were instantly refrigerated using cold packs and transported to the research lab within two hours of blood collection. Serum ferritin, transferrin receptors and lead levels were tested using chemiluminescence immunoassay, immunoturbidimetry and Graphite Furnace Atomic Absorption Spectroscopy (GFAAS) method respectively in the Biochemistry department, Christian Medical College, Vellore. As inflammation can influence serum ferritin levels, both transferrin (R) and ferritin (F) levels were utilized to find total body iron levels using the formula, where positive values indicate iron reserves [33]:

$$
\operatorname{BodyIron}(\mathrm{mg} / \mathrm{kg})=\left(\frac{-\left(\log \left(\frac{R}{F} \text { ratio }\right)-2.8229\right)}{0.1207}\right)
$$

\section{Data entry and analysis}

Data entry was made in the double entry database system managed by Data Coordinating Centre (DCC) of the MAL-ED study. Data collection forms filled by the field workers were authenticated by the field 
supervisor before entering into the database [21]. Data analysis was done using Stata version 13 (StataCorp. 2013. Stata Statistical Software. Release 13. College station, TX: StataCorp LP).

\section{Statistical analysis}

The outcome variable, BSID scores, assessed at 6, 15, 24 and 36 months of age was summarized using mean and standard deviation (SD) under specific domains namely - cognitive, language, motor and socioemotional domain. Independent predictors such as maternal depression score, maternal cognition and various domains of HOME inventory scale were summarized as mean and SD. Height-for-age and weightfor age scores below - 2 SD were categorized as stunted and underweight respectively. Values of blood iron measured at 7, 15 and 24 months were considered for analysis and the missing values were replaced with the average of measurements available at the other time points. Blood lead levels measured at 15 , 24 and 36 months were averaged to obtain mean lead level. Generalized estimating equations were used to find the predictors of cognitive development scores under each domain separately, using exchangeable correlation matrix. Model fit was assessed using Wald statistics and $p$ less than 0.05 was considered as statistical significance.

\section{Results}

In the original birth-cohort, 251 newborns were enrolled after registering 301 pregnant mothers. 50 children were excluded as per the exclusion criteria: another sibling registered in the MAL-ED study $(n=8)$, medical comorbidities in children $(n=7)$, multiple pregnancy $(n=1)$, pre-existing plan to migrate $(n=5)$, mother not available for consent $(n=9)$, combination of two or more of the above mentioned reasons ( $n$ $=10)$ and mothers/parents refused participation $(n=10)$. Subsequent 6-month, 2-year and 3-year follow ups had 235 children, 228 children and 218 children respectively. Migration was the main cause for the loss to follow-up, as illustrated in other published articles from the same cohort [34].

The Vellore birth-cohort had a mean birth weight (SD) of $2.8(0.44) \mathrm{kg}$ and $17 \%$ of newborns weighed less than $2.5 \mathrm{~kg}$. The mean family size was 5.7 ranging from 3 to 13 and mean (SD) body mass index of mothers was $22(3.9) \mathrm{kg} / \mathrm{m}^{2}$. More than $80 \%$ of families had monthly income less than 5000 Indian rupees. The cohort had girl predominance at birth (56\%) as well as subsequent follow-ups (Table 1 ). Cohort characteristics at 6 and 36 months are summarized in Table 1. 
Table 1

Baseline characteristics of the birth cohort established in Vellore in 2010

\begin{tabular}{|c|c|c|}
\hline Variables & 6 months $(n=235)$ & $\begin{array}{l}36 \text { months }(\mathrm{n}= \\
218)\end{array}$ \\
\hline Sex $(\%)$ & $\begin{array}{l}\text { Female: } 129 \\
(54.9 \%)\end{array}$ & $116(53.3 \%)$ \\
\hline HOME total score, mean (SD) & $40.77(3.24)$ & $40.27(3.18)$ \\
\hline \multicolumn{3}{|c|}{ Domain-wise score of HOME inventory score, mean (SD) } \\
\hline Emotional and verbal responsivity of caregiver, & $10.60(1.10)$ & $11(0.07)$ \\
\hline Avoidance of restriction and punishment & $4.68(0.52)$ & $4.12(0.46)$ \\
\hline Caregiver promotes child development & $4.67(0.69)$ & $4.96(0.20)$ \\
\hline $\begin{array}{l}\text { Organization of physical and temporal } \\
\text { environment }\end{array}$ & $10.32(1.37)$ & $9.49(1.49)$ \\
\hline Provision of appropriate play materials & $2.24(0.69)$ & $2.66(0.48)$ \\
\hline Opportunities for variety in daily stimulation & $5.38(1.57)$ & $5.75(1.56)$ \\
\hline Cleanliness of child & $2.87(0.43)$ & $2.28(0.85)$ \\
\hline WAMI score, mean (SD) & $0.453(0.15)$ & $0.54(0.17)$ \\
\hline Maternal depression (SRQ) score, mean (SD) & $4.53(3.74)$ & $3.82(3.53)$ \\
\hline Maternal cognition raw score, mean (SD) & $43.90(10.49)$ & - \\
\hline
\end{tabular}

Developmental domain quotients of cognition, language, motor and social skills significantly differed between 6 and 36 months of age (Table 2) with both cognition and social domains showing a decline of more than 15 points (Fig. 1).

Table 2:

Mean (SD) domain quotient scores of Bayley Scales of Infant Development -III at 6, 15,24 and 36 months

\begin{tabular}{|llllll|}
\hline & 6 months & 15 months & 24 months & 36 months & P-value \\
Cognition & $102.4(9.9)$ & $101.5(9.6)$ & $92.5(6.9)$ & $86.5(4.6)$ & $<0.0001$ \\
Language & $98.0(8.4)$ & $98.1(8.9)$ & $98.0(9)$ & $93.1(4.4)$ & $<0.0001$ \\
Motor & $106(14.1)$ & $100.1(8.5)$ & $103.3(8.7)$ & $99.2(7.2)$ & $<0.0001$ \\
Social & $115.7(13.4)$ & $116.7(11.6)$ & $113.7(10)$ & $98.7(4.1)$ & $<0.0001$ \\
\hline
\end{tabular}


Analysing factors responsible for the change in cognition scores between 6 and 36 months, higher SES, body iron levels and HOME factors of parental responsivity and provision of appropriate play materials positively predicted cognition (Table 3). The maximum positive association was with SES followed by HOME factors, while stunting had the maximum negative impact. Higher maternal cognition, higher SES, and caregiver responsivity positively contributed to language change over time, while higher maternal depression contributed negatively. Maximum effect size on language change was seen with SES. 
Table 3

Factors associated with child development scores measured at 6, 15, 24 and 36 months in Vellore cohort of MAL-ED study $(\mathrm{N}=216)$

\begin{tabular}{|c|c|c|c|}
\hline \multirow[t]{2}{*}{ Factors } & \multicolumn{3}{|c|}{ Adjusted beta co-efficient with $95 \% \mathrm{Cl}$} \\
\hline & $\begin{array}{l}\text { Cognitive } \\
\text { domain }\end{array}$ & $\begin{array}{l}\text { Language } \\
\text { domain }\end{array}$ & Motor domain \\
\hline Female & $\begin{array}{l}0.51(-0.67- \\
1.69)\end{array}$ & $\begin{array}{l}1.14(-0.05- \\
2.32)\end{array}$ & $\begin{array}{l}1.54(-0.04- \\
3.11)\end{array}$ \\
\hline Mother's cognition score & $\begin{array}{l}0.03(-0.03- \\
0.09)\end{array}$ & $\begin{array}{l}0.09(0.03- \\
0.14)\end{array}$ & $\begin{array}{l}0.09(0.01- \\
0.17)\end{array}$ \\
\hline Stunted (<-2SD) & $\begin{array}{l}-1.66(-3.22- \\
-0.09)\end{array}$ & $\begin{array}{l}0.13(-1.22- \\
1.48)\end{array}$ & $\begin{array}{l}-1.95(-3.63- \\
-0.26)\end{array}$ \\
\hline Underweight (<-2SD) & $\begin{array}{l}-0.54(-2.12- \\
1.04)\end{array}$ & $\begin{array}{l}-1.34(-2.75- \\
0.08)\end{array}$ & $\begin{array}{l}-2.41(-4.19- \\
-0.62)\end{array}$ \\
\hline \multicolumn{4}{|l|}{ WAMI scores } \\
\hline Middle (33rd - 66th percentile) & $\begin{array}{l}1.08(-0.54- \\
2.69)\end{array}$ & $\begin{array}{l}1.39(-0.04- \\
2.81)\end{array}$ & $\begin{array}{l}0.83(-0.96- \\
2.63)\end{array}$ \\
\hline High (> 66th percentile) & $\begin{array}{l}1.86(0.26- \\
3.46)\end{array}$ & $\begin{array}{l}1.73(0.23- \\
3.23)\end{array}$ & $\begin{array}{l}1.59(-0.35- \\
3.52)\end{array}$ \\
\hline Body iron levels & $\begin{array}{l}0.18(0.05- \\
0.30)\end{array}$ & $\begin{array}{l}0.05(-0.05- \\
0.15)\end{array}$ & $\begin{array}{l}0.30(0.17- \\
0.43)\end{array}$ \\
\hline Mean blood lead levels & $\begin{array}{l}-0.03(-0.14- \\
0.09)\end{array}$ & $\begin{array}{l}-0.07(-0.19- \\
0.05)\end{array}$ & $\begin{array}{l}-0.04(-0.19- \\
0.12)\end{array}$ \\
\hline Mother's depression scores & $0(-0.19-0.18)$ & $\begin{array}{l}-0.23(-0.39- \\
-0.06)\end{array}$ & $\begin{array}{l}-0.04(-0.25- \\
0.18)\end{array}$ \\
\hline \multicolumn{4}{|l|}{ Domain scores of HOME Inventory scale } \\
\hline $\begin{array}{l}\text { Emotional and verbal responsivity of } \\
\text { caregiver }\end{array}$ & $\begin{array}{l}0.92(0.11- \\
1.73)\end{array}$ & $1.0(0.15-1.75)$ & $\begin{array}{l}1.30(0.24- \\
2.36)\end{array}$ \\
\hline Avoidance of restriction and punishment & $\begin{array}{l}0.68(-0.50- \\
1.87)\end{array}$ & $\begin{array}{l}0.21(-0.97- \\
1.39)\end{array}$ & $\begin{array}{l}1.91(0.35- \\
3.48)\end{array}$ \\
\hline Caregiver promotes child development & $\begin{array}{l}1.03(-0.13- \\
2.18)\end{array}$ & $\begin{array}{l}1.09(-0.07- \\
2.25)\end{array}$ & $\begin{array}{l}0.68(-0.86- \\
2.22)\end{array}$ \\
\hline $\begin{array}{l}\text { Organization of physical and temporal } \\
\text { environment }\end{array}$ & $0.11(-32-0.55)$ & $\begin{array}{l}0.36(-0.08- \\
0.79)\end{array}$ & $\begin{array}{l}-0.12(-0.70- \\
0.46)\end{array}$ \\
\hline Provision of appropriate play materials & $\begin{array}{l}0.98(0.06- \\
1.91)^{(1)}\end{array}$ & $\begin{array}{l}0.39(-0.53 \\
-1.30)\end{array}$ & $\begin{array}{l}1.38(0.16- \\
2.59)\end{array}$ \\
\hline Opportunities for variety in daily stimulation & $\begin{array}{l}-0.02(-0.44- \\
0.40)\end{array}$ & $\begin{array}{l}0.14(-0.29- \\
0.56)\end{array}$ & $\begin{array}{l}-0.40(-0.96- \\
0.17)\end{array}$ \\
\hline
\end{tabular}


Factors positively contributing to change in motor scores included, higher maternal cognition, higher weight and height for age scores, higher body iron levels and positive home factors of emotional and verbal responsivity of caregiver, avoidance of restriction and punishment, and availability of appropriate play materials. Both HOME factors and growth parameters had high association with change in motor skills. Body iron levels positively influenced social domain change over time with beta-coefficient $(95 \% \mathrm{Cl})$ of $0.20(0.05-0.34)$, while blood lead levels had a negative influence with beta-coefficient $(95 \% \mathrm{Cl})$ of $-0.22(-0.34-0.09)$ in univariate analyses. There was no significant associations in multivariate analysis, thus not reported in Table 3.

\section{Discussion}

This prospective longitudinal birth cohort follow-up analysis from urban Vellore evaluated developmental trends in the domains of cognition, language, motor and social skills; and predictors for individual domain change over time. All developmental domain quotients showed a decreasing trend over time with cognition and language domains dropping more than 15 points between 6 and 36 months of age. Children in the highest tertile of SES had better cognition and language scores over time. Stunted children had poorer cognition and motor scores over time. Home environmental factors of parental responsivity affected changes in cognition, language and motor scores, while punishment avoidance and toy availability influenced the motor score change. Higher maternal cognition affected changes in both language and motor domains, while maternal depression adversely affected language scores over time. Body iron levels was associated with changes in all cognition and motor skills. There was good level of follow-up in the current study with $94 \%$ at 6 months, $91 \%$ at 24 months and $87 \%$ at 36 months.

Child development evolves over time and developmental measures such as BSID-III have shown weak predictability of school age cognition [35], motor skills [36], and behaviour [37]. Despite this, BSID is the most common developmental tool used across the globe, as it is a sensitive measure of child development [23]. Though child developmental process and sequence are uniform across the world, there can be differences in the rate of achievement between populations. Trends of all developmental domains in an urban low-income setting as shown in this study can be useful for clinical practice in such settings, academic understanding, and analysing the risks contributing to any setback. Though the current analysis has not done a complete trajectory exploration, the birth cohort showed a decreasing trend in all developmental domains' quotient. This is in discordance with another large rural birth cohort study reported from China, where more than $90 \%$ showed an increasing trend in cognitive development between 6 and 24 months of age [9]. The Vellore birth cohort is predominantly a low-income urban slum setting with additional environmental and nutritional challenges, which have been explored in the current analysis. Similar results were reported from another study conducted in rural India, where recruited infants showed a decline in scores in fine motor, receptive and expressive language skills and visual reception over a 6-month follow-up period [38].

The SES including household wealth affects linear growth [39, 40], development [2] and cognition [15, 41] in children. Childhood SES is shown to influence neural development particularly of the language and 
executive function areas in the brain [42]. Better SES can result in improved nutrition, better sanitation, less infection and enhanced interactive experiences, all of which can improve child development especially language as shown in the current study.

Stunting had independent associations with cognition and motor scores despite correction with SES, HOME status and micronutrient levels in the current study. Stunting has been shown to affect development and cognition; thus integrated interventions have been suggested to improve both linear growth and child development [2,5]. A rural study conducted in Telangana, South India found similar results where height z-scores at enrollment had a positive association with all child development domains, the effect of which was attenuated by a nurturing home environment [38].

In the current study, positive home environmental factors influenced developmental gains over time, despite correction with SES. Home environment can mediate the relationship between SES and early childhood development $[15,16]$ as well as between linear growth and development [38]. The two components of home environment - physical and relational modulate each other with the sensitive and interactive relational factor overriding the negative effects of a sub-optimal home milieu. The effect of physical overcrowding on childhood development and cognition has been mediated by maternal responsiveness [43].

Maternal factors can influence child development, cognition and behaviour directly and indirectly through better home environmental factors. The effect of maternal depression can even start in the ante-natal period not only through altered placental functions, but also through foetal epigenetic changes and stress reactivity [14]. Maternal cognition also affects childhood development and cognition through genetic factors as well as enriching interacting experiences $[8,15,43]$.

Iron deficiency in early childhood, when there is increased iron demand to optimize neuronal maturation, neurotransmitter synthesis, mitochondrial function and other iron dependent enzymes [44], can be detrimental as shown in the current analysis. This early childhood iron deficiency can have persisting effects on cognition in later life as evidenced by another analysis on the same cohort showing cumulative iron deficiency negatively impacting verbal, performance and processing speed domains of cognition at five years of age [34]. That assessment had shown that more than $40 \%$ of children had iron deficiency at 15 and 24 months of age. Later childhood iron supplementation improves body iron stores, but not the persisting effect of early onset iron deficiency on cognition $[44,45]$.

There are limitations for the current study including a comparatively small sample size. Though BSID-III is a sensitive and adapted measure, there can be variations (within normal limits) in developmental achievements. However the low-income urban slum setting of the cohort, its high early childhood iron deficiency and a significant decline in developmental quotients over time warrant an assessment as in the current study. Strengths of the study include good follow-ups of a longitudinal birth cohort, strong data granularity during early childhood period, standardized developmental, home environment and SES assessments, blood results from a national reference laboratory and rigorous quality control measures internally and externally. 


\section{Conclusions}

This longitudinal birth cohort follow-up study has shown a significant decline in developmental scores in cognition, language, motor and social domains between 6 and 36 months of age in a LMIC urban slum setting. Positive home environmental factors in addition to SES enhanced developmental outcomes. Both maternal components of cognition and depression showed effects on progress of child development. Linear growth as well as iron deficiency independently influenced development. A triple intervention plan to enhance home environment and nurturance, maternal education and well-being, and early childhood nutrition supplementation might prevent child developmental decline in high risk settings.

\section{Declarations}

\section{Acknowledgements}

The authors thank the participants, their families and staff of the MAL-ED Network project

\section{Financial support}

The Etiology, Risk Factors and Interactions of Enteric Infections and Malnutrition and the Consequence for Child Health and Development Project (MAL-ED) is carried out as a collaborative project supported by the Bill and Melinda Gates Foundation, the Foundation for the $\mathrm{NIH}$ and the National Institutes of Health/Fogarty International Center.

\section{Conflict of Interest}

None

\section{Author contribution}

Drs. GK, SJ, AB, VRM, RR and BK are involved in the birth cohort study planning, recruitment and followup as well as in the planning, analysis, write-up and correction of the current study. Drs. MS is involved in the data analysis, write-up and corrections. Mr. KR is the data co-ordinator, who entered and analysed data and is involved in the study write-up and corrections. All authors approved the final manuscript.

\section{Ethical Standards disclosure}

This study was conducted according to the guidelines laid down in the Declaration of Helsinki and all procedures involving human subjects/patients were approved by the Institutional Review Board, Christian Medical College, Vellore. Written informed consent was obtained from all participants' parents. 
MAL-ED data from all sites are deposited in the https://clinepidb.org website.

\section{References}

1. Grantham-McGregor S, Cheung YB, Cueto S, Glewwe P, Richter L, Strupp B: Developmental potential in the first 5 years for children in developing countries. Lancet 2007, 369(9555):60-70.

2. Black MM, Walker SP, Fernald LCH, Andersen CT, DiGirolamo AM, Lu C, McCoy DC, Fink G, Shawar YR, Shiffman $\mathrm{J}$ et al: Early childhood development coming of age: science through the life course. Lancet 2017, 389(10064):77-90.

3. Lu C, Black MM, Richter LM: Risk of poor development in young children in low-income and middleincome countries: an estimation and analysis at the global, regional, and country level. Lancet Glob Health 2016, 4(12):e916-e922.

4. Biesalski HK: The 1,000-Day Window and Cognitive Development. World Rev Nutr Diet 2016, 115:115.

5. Black MM, Pérez-Escamilla R, Rao SF: Integrating nutrition and child development interventions: scientific basis, evidence of impact, and implementation considerations. Adv Nutr 2015, 6(6):852859.

6. Georgiadis A, Penny ME: Child undernutrition: opportunities beyond the first 1000 days. Lancet Public Health 2017, 2(9):e399.

7. MAL-ED Network Investigators: Early childhood cognitive development is affected by interactions among illness, diet, enteropathogens and the home environment: findings from the MAL-ED birth cohort study. BMJ Glob Health 2018, 3(4):e000752.

8. McCormick BJJ, Richard SA, Caulfield LE, Pendergast LL, Seidman JC, Koshy B, Roshan R, Shrestha R, Svensen E, Blacy L et al: Early Life Child Micronutrient Status, Maternal Reasoning, and a Nurturing Household Environment have Persistent Influences on Child Cognitive Development at Age 5 years: Results from MAL-ED. J Nutr 2019, 149(8):1460-1469.

9. Zhu Z, Chang S, Cheng Y, Qi Q, Li S, Elhoumed M, Yan H, Dibley MJ, Fawzi WW, Zeng L et al: Early life cognitive development trajectories and intelligence quotient in middle childhood and early adolescence in rural western China. Sci Rep 2019, 9(1):18315-18315.

10. Prado EL, Dewey KG: Nutrition and brain development in early life. Nutr Rev 2014, 72(4):267-284.

11. Humphrey JH, Jones AD, Manges A, Mangwadu G, Maluccio JA, Mbuya MN, Moulton LH, Ntozini R, Prendergast AJ, Stoltzfus RJ et al: The Sanitation Hygiene Infant Nutrition Efficacy (SHINE) Trial: Rationale, Design, and Methods. Clin Infect Dis 2015, 61 Suppl 7(Suppl 7):S685-702.

12. Ajjampur SSR, Koshy B, Venkataramani M, Sarkar R, Joseph AA, Jacob KS, Ward H, Kang G: Effect of cryptosporidial and giardial diarrhoea on social maturity, intelligence and physical growth in children in a semi-urban slum in south India. Ann Trop Paediatr 2011, 31(3):205-212. 
13. Tarleton JL, Haque R, Mondal D, Shu J, Farr BM, Petri WA, Jr.: Cognitive effects of diarrhea, malnutrition, and Entamoeba histolytica infection on school age children in Dhaka, Bangladesh. Am $J$ Trop Med Hyg 2006, 74(3):475-481.

14. Herba CM, Glover V, Ramchandani PG, Rondon MB: Maternal depression and mental health in early childhood: an examination of underlying mechanisms in low-income and middle-income countries. Lancet Psychiat 2016, 3(10):983-992.

15. Ronfani L, Vecchi Brumatti L, Mariuz M, Tognin V, Bin M, Ferluga V, Knowles A, Montico M, Barbone F: The Complex Interaction between Home Environment, Socioeconomic Status, Maternal IQ and Early Child Neurocognitive Development: A Multivariate Analysis of Data Collected in a Newborn Cohort Study. PLoS One 2015, 10(5):e0127052.

16. Contreras D, González S: Determinants of early child development in Chile: Health, cognitive and demographic factors. Int J Educ Dev 2015, 40:217-230.

17. Lynch JL, Gibbs BG: Birth Weight and Early Cognitive Skills: Can Parenting Offset the Link? Matern Child Health J 2017, 21(1):156-167.

18. Nicholson JM, Rempel LA: Australian and New Zealand birth cohort studies: breadth, quality and contributions. J Paediatr Child Health 2004, 40(3):87-95.

19. Takahashi Y, Okada K, Hoshino T, Anme T: Developmental Trajectories of Social Skills during Early Childhood and Links to Parenting Practices in a Japanese Sample. PLoS One 2015, 10(8):e0135357.

20. Kar BR, Rao SL, Chandramouli BA, Thennarasu K: Growth patterns of neuropsychological functions in Indian children. Front Psycho/ 2011, 2:240-240.

21. MAL-ED Network Investigators: The MAL-ED study: a multinational and multidisciplinary approach to understand the relationship between enteric pathogens, malnutrition, gut physiology, physical growth, cognitive development, and immune responses in infants and children up to 2 years of age in resource-poor environments. Clin Infect Dis 2014, 59 Suppl 4:S193-206.

22. John SM, Thomas RJ, Kaki S, Sharma SL, Ramanujam K, Raghava MV, Koshy B, Bose A, Rose A, Rose W et al: Establishment of the MAL-ED birth cohort study site in Vellore, Southern India. Clin Infect Dis 2014, 59 Suppl 4:S295-299.

23. Bayley N: Bayley scales of infant and toddler development III. San Antonio, TX: Psychological Corp; 2005.

24. Murray-Kolb LE, Rasmussen ZA, Scharf RJ, Rasheed MA, Svensen E, Seidman JC, Tofail F, Koshy B, Shrestha R, Maphula A et al: The MAL-ED cohort study: methods and lessons learned when assessing early child development and caregiving mediators in infants and young children in 8 lowand middle-income countries. Clin Infect Dis 2014, 59 Suppl 4:S261-272.

25. Psaki SR, Seidman JC, Miller M, Gottlieb M, Bhutta ZA, Ahmed T, Ahmed AS, Bessong P, John SM, Kang $\mathrm{G}$ et al: Measuring socioeconomic status in multicountry studies: results from the eight-country MAL-ED study. Popul Health Metr 2014 Mar 21;12(1):8 doi: 101186/1478-7954-12-8 2014.

26. Caldwell B, Bradley, R. : Home observation for the measurement of the environment. Little Rock: University of Arkansas; 1984. 
27. Elardo R, Bradley RH: The home observation for measurement of the environment (HOME) scale: $A$ review of research. Developmental Review 1981, 1(2):113-145.

28. Black MM, Baqui AH, Zaman K, Ake Persson L, El Arifeen S, Le K, McNary SW, Parveen M, Hamadani JD, Black RE: Iron and zinc supplementation promote motor development and exploratory behavior among Bangladeshi infants. Am J Clin Nutr 2004, 80(4):903-910.

29. Murray-Kolb LE, Rasmussen ZA, Scharf RJ, Rasheed MA, Svensen E, Seidman JC, Tofail F, Koshy B, Shrestha R, Maphula A et al: The MAL-ED Cohort Study: Methods and Lessons Learned When Assessing Early Child Development and Caregiving Mediators in Infants and Young Children in 8 Low- and Middle-Income Countries. Clinical Infectious Diseases: An Official Publication of the Infectious Diseases Society of America 2014, 59(Suppl 4):S261-S272.

30. Jones PC, Pendergast LL, Schaefer BA, Rasheed M, Svensen E, Scharf R, Shrestha R, Maphula A, Roshan R, Rasmussen $Z$ et al: Measuring home environments across cultures: Invariance of the HOME scale across eight international sites from the MAL-ED study. J Sch Psychol 2017, 64:109127.

31. Raven J, Raven, JC., Court, JH. : Manual for Raven's Progressive Matrices and Vocabulary Scales. San Antonio, TX: Harcourt Assessment; 2003.

32. Beusenberg M, Orley, J.A.: Users guide to the Self Reporting Questionnaire (SRQ). Geneva, Switzerland: World Health Organisation; 1994.

33. Cook JD, Flowers CH, Skikne BS: The quantitative assessment of body iron. Blood 2003, 101(9):3359-3364.

34. Koshy B, Srinivasan M, Zachariah SM, Karthikeyan AS, Roshan R, Bose A, Mohan VR, John S, Ramanujam K, Muliyil $\mathrm{J}$ et al: Body iron and lead status in early childhood and its effects on development and cognition: a longitudinal study from urban Vellore. Public Health Nutr 2020:1-11.

35. Pollitt E, Triana N: Stability, Predictive Validity, and Sensitivity of Mental and Motor Development Scales and Pre-School Cognitive Tests among Low-Income Children in Developing Countries. Food Nutr Bull 1999, 20(1):45-52.

36. Spittle AJ, Spencer-Smith MM, Eeles AL, Lee KJ, Lorefice LE, Anderson PJ, Doyle LW: Does the BayleyIII Motor Scale at 2 years predict motor outcome at 4 years in very preterm children? Dev Med Child Neurol 2013, 55(5):448-452.

37. Gould JF, Hunt E, Roberts RM, Louise J, Collins CT, Makrides M: Can the Bayley Scales of Infant Development at 18 months predict child behaviour at 7 years? J Paediatr Child Health 2019, 55(1):74-81.

38. Black MM, Yimgang DP, Hurley KM, Harding KB, Fernandez-Rao S, Balakrishna N, Radhakrishna KV, Reinhart GA, Nair KM: Mechanisms linking height to early child development among infants and preschoolers in rural India. Dev Sci 2019, 22(5):e12806.

39. Danaei G, Andrews KG, Sudfeld CR, Fink G, McCoy DC, Peet E, Sania A, Smith Fawzi MC, Ezzati M, Fawzi WW: Risk Factors for Childhood Stunting in 137 Developing Countries: A Comparative Risk 
Assessment Analysis at Global, Regional, and Country Levels. PLoS medicine 2016, 13(11):e1002164-e1002164.

40. Sudfeld CR, Charles McCoy D, Danaei G, Fink G, Ezzati M, Andrews KG, Fawzi WW: Linear Growth and Child Development in Low- and Middle-Income Countries: A Meta-Analysis. Pediatrics 2015, 135(5):e1266-e1275.

41. Hamadani JD, Tofail F, Huda SN, Alam DS, Ridout DA, Attanasio O, Grantham-McGregor SM: Cognitive Deficit and Poverty in the First 5 Years of Childhood in Bangladesh. Pediatrics 2014, 134(4):e1001-e1008.

42. Hackman DA, Farah MJ, Meaney MJ: Socioeconomic status and the brain: mechanistic insights from human and animal research. Nat Rev Neurosci 2010, 11(9):651-659.

43. Evans GW, Ricciuti HN, Hope S, Schoon I, Bradley RH, Corwyn RF, Hazan C: Crowding and Cognitive Development: The Mediating Role of Maternal Responsiveness Among 36-Month-Old Children. Environ Behav 2009, 42(1):135-148.

44. Jảuregui-Lobera I: Iron deficiency and cognitive functions. Neuropsychiatr Dis Treat 2014, 10:20872095.

45. Beard JL, Connor, J.R.: Iron status and neural functioning. Ann Rev Nutr 2003, 23:31-58.

\section{Figures}
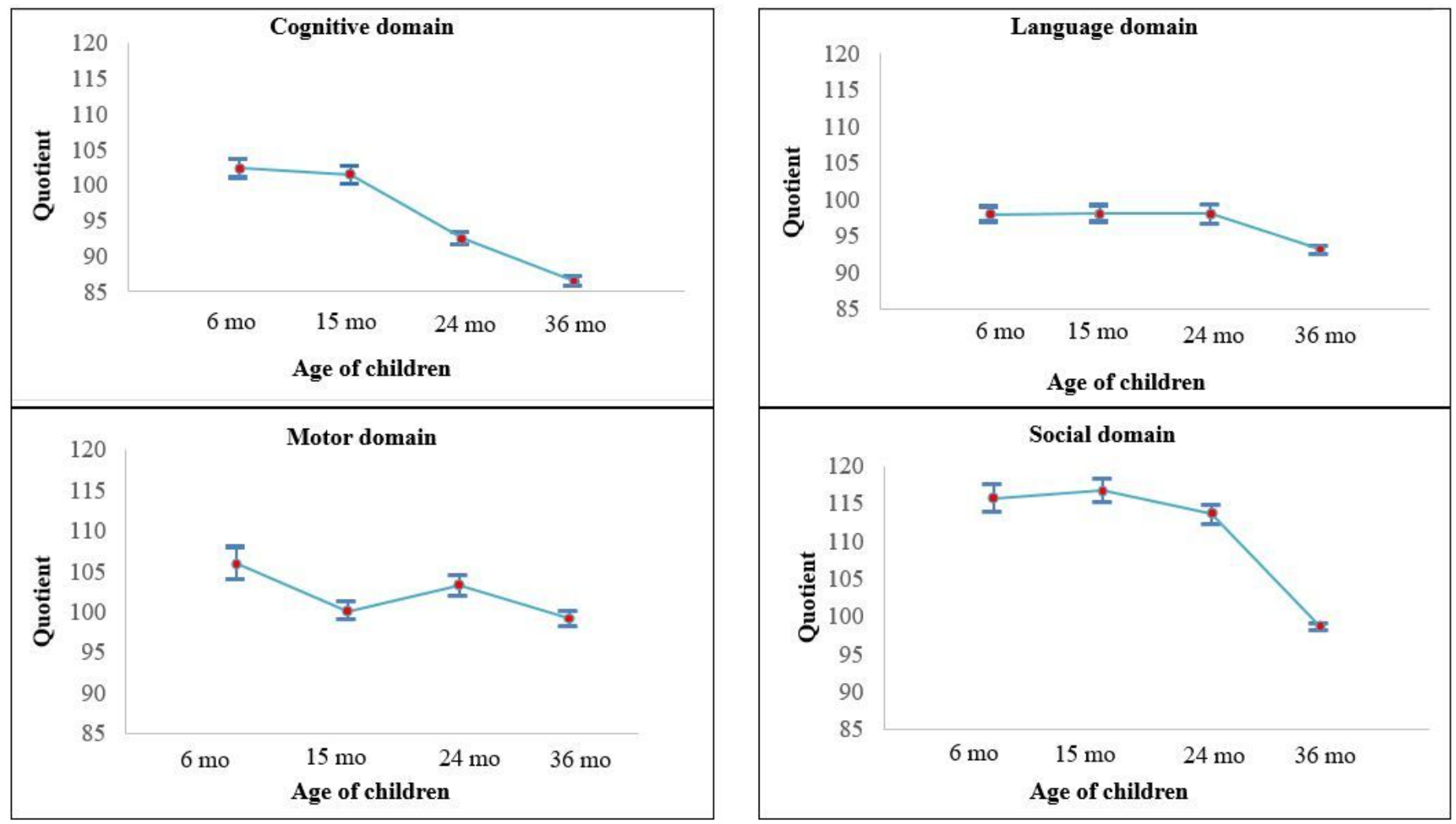

Figure 1 
Domain wise scores obtained in Bayley scales of infant development assessed between 6 and 36 months of age in children of MAL-ED cohort, Vellore. 